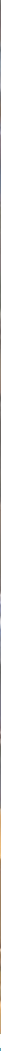

EIDOS, 4

Marzo-agosto 2011, 26-30

ISSN:1390-499X

elSSN:1390-5007

\title{
SISTEMA DE VISION ARTIFICIAL PARA EL ANALISIS EN LA COMPOSICIÓN GRANULOMETRICA DEL GRANULADO DE HIERRO
}

M. Trufanov, I. Chernetskaya, H. Concha', Universidad Estatal del Sur-Oeste de Rusia

Recepción/Received: 2011-03-29

Aceptación/Accepted: 2011-07-11

Publicado/Published: 2011-08-05

Resumen -En el artículo se presentan los resultados de las investigaciones experimentales de un sistema de visión artificial, desarrollado para medir los parámetros de las granulaciones, este experimento confirma la viabilidad y conveniencia de utilizar un sistema de este tipo dentro del proceso tecnológico de producción, que dependerá básicamente del análisis realizado por el sistema adaptivo de distribución de partículas.

\section{Palabras clave -Visión artificial, Granulación}

Abstract -This article presents results obtained from an experimental research of an artificial vision system, developed to measure granulation benchmarks; this experiment confirms feasibility and convenience of using this kind of system in the technological production process, which will depend basically on the analysis made by a particle distribution adaptive system.

Keywords -Artificial Vision, Granulation 


\section{INTRODUCCIÓN}

En el proceso de la formación del granulo es presentado un sistema óptico para el análisis técnico en la medición de los parámetros del gránulo al caer del tamiz y los resultados arrojados por las investigaciones experimentales. La aplicación del sistema al aumentar la flexibilidad y la racionalidad del proceso tecnológico.

El control del proceso de granulación de los materiales sueltos del mineral de hierro es un aspecto fundamental en la obtención del mineral, durante la producción de aleaciones de hierro.

Según uno de los esquemas tecnológicos más comunes, la granulación se realiza en una granuladora de tambor (rotativa), donde se mezclan y compactan los materiales. El proceso de granulación es cíclico, el material granulado se descarga del tambor y se clasifica mediante un sistema acústico, luego se vuelve a cargar a la granuladora para la posterior formación, hasta alcanzar la clase exigida.

Tradicionalmente las características de la materia prima y la composición granulométrica es controlada en laboratorio, una vez terminado el proceso de granulación, se toma una muestra aleatoria para la definición de sus parámetros y en base a esta información se toman decisiones sobre el manejo y la calidad de la producción obtenida [1]. En el trabajo [2] se propone un método de control y manejo del proceso de granulación, mediante un análisis de los parámetros de los gránulos del mineral de hierro, durante el proceso de formación de los mismos (producto intermedio), que permite controlar el proceso cercano al tiempo real, sin embargo, el proceso es indirecto (por consiguiente, no siempre proporciona exactitud en la medición).

En las condiciones actuales, donde existen métodos opto-electrónicos modernos bastante desarrollados para el control y medición de los parámetros en distintos procesos tecnológicos, una opción válida para resolver las tareas de análisis de la composición granulada en los grumos es el uso de sistemas de visión artificial, que permiten medir los parámetros geométricos del producto intermedio en el proceso de granulación pasado por el sistema acústico. Esto permite en tiempo real obtener datos sobre la composición granulada y la masa de los gránulos formados en la granuladora de tambor (con base en el análisis de texturas) con mayor exactitud en comparación con métodos análogos.

El análisis de la literatura científica-técnica y patentes en el campo de la producción de los gránulos, a partir de material finamente molido, ha mostrado la ausencia de métodos "sin contacto" que permita definir los parámetros de los granos en tiempo real, con la finalidad de automatizar los proceso de producción.

Así pues, en la Federación Rusa son conocidos los trabajos de Ershov E.V. [3] para la automatización de la medición de parámetros de encendido de lotes en la máquina de sinterización de producción en cadena y el trabajo de Selivanovsky V.V. [4] sobre la medida de los parámetros de sinterización basados en métodos de procesamiento de imágenes. Son también conocidos trabajos de autores extranjeros que se relacionan indirectamente con la medición "sin contacto" directo con los gránulos (ver ejemplo [5]).

\section{SISTEMA DE LA VISIÓN ARTIFICIAL}

El sistema de la visión artificial (SVA) propuesto consiste en dos módulos individuales, comunicados mediante un canal de radio (Fig. 1) en la frecuencia 2,4 GHz. El primer módulo incluye los dispositivos para la recepción de las imágenes, el segundo constituye los medios del procesamiento de las imágenes y el cálculo de los parámetros buscados en los gránulos.

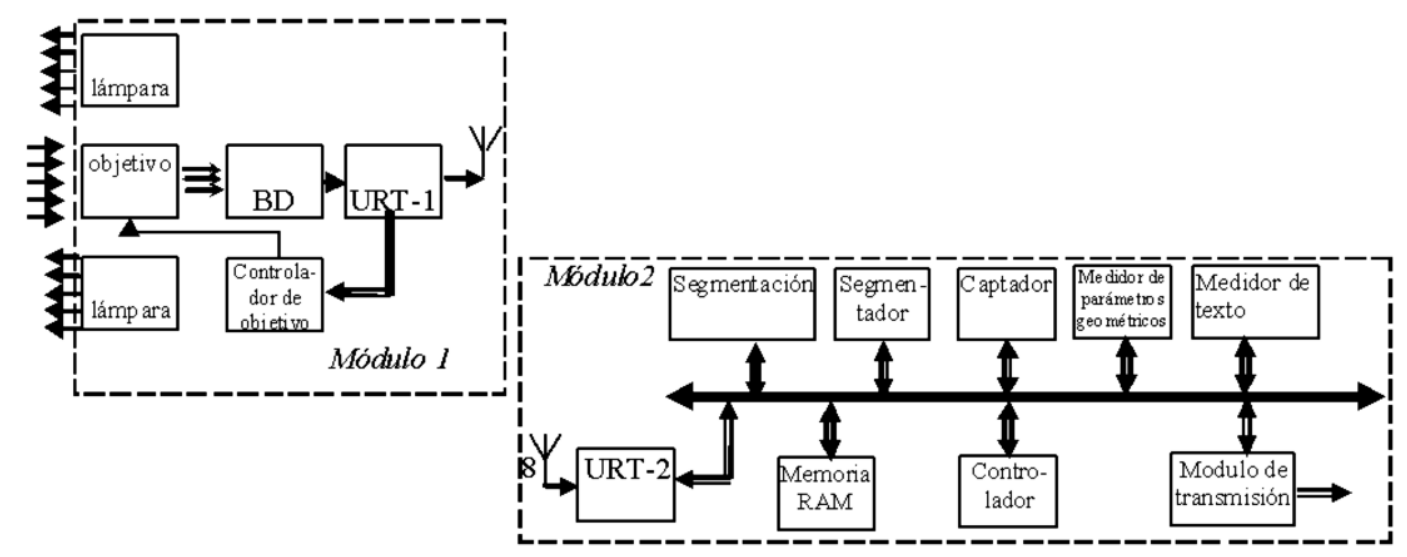

Figura1. Sistema de visión artificial del análisis técnico en la composición granulométrica del granulado de hierro 
El primer módulo incluye una lente con un diafragma no inferior a 2,8, un censor de imagen de vídeo, una unidad transmisor-receptor UTR-1, dos lámparas, controlador de la lente, una antena. El segundo módulo contiene una antena, una unidad transmisor-receptor UTR -2, una memoria RAM, un módulo para difinir los bordes en las imagenes, un módulo de segmentación, detector de gránulos, el medidor de parámetros geométricos, el medidor de texturas, un controller, que coordina el trabajo de todos los módulos y el módulo de transmisión.

El sistema de la visión artificial funciona de la siguiente manera: Se enfocan las lámparas al lugar donde caen los gránulos del tamiz. La imagen de los gránulos en caída pasa a través de la lente, hacia el censor de vídeo, el cual mediante el canal de la radio transmite a la memoria RAM del módulo 2.

La lente rápida es necesaria para lograr dos objetivos:

- La selección de los gránulos enfocando hacia el lugar de su caída, que permite una selección espacial adicional y por lo tanto minimiza el problema de cálculo de procedimientos en la selección de imágenes de los gránulos;

- Suficiente "selección" de flujo luminoso para lograr una velocidad lenta de obturación en el censor de vídeo con el fin de obtener imágenes con poco efecto de ruido en los gránulos y sin efecto de desenfoque.

El controlador cumple las funciones de árbitro, es decir coordina el trabajo de todos los bloques del módulo 2, como también realiza operaciones sencillas de procesamiento de las imagenes.

El módulo de deteccion de bordes, lee sucesivamente de la memoria RAM ciertas partes de la imagen y obtiene una imagen diferenciada [6]. La cual posteriormente es tratada por el controlador para:

- Forma contornos (bordes) utilizando la posicion secuencial y cercana de los puntos de la imagen diferenciada y graba el conjunto de bordes en la memoria RAM;

- Determina la nitidez de la imagen, mediante áreas selectivas en la parte central de la imagen diferenciada y en caso necesario da la orden para corregir la nitidez del lente y obtener una imagen más clara.

El módulo de segmentación realiza una segmentación de la imagen inicial, y como el resultado se forma la imagen segmentada con centros hipotéticos de los gránulos. La imagen segmentada se almacena en RAM.

Después de calcular las imagenes segmentada, diferenciada y los conjuntos de bordes almacenados en la RAM, el detector de gránulos "bolitas" analiza, mediante la busqueda cerca a los centros segmentados de bordes y confirma $u$ objeta la existencia de los gránulos en la imagen, como partes segmentadas anteriormente.

De esta forma, en esta etapa en la imagen se determina una cierta cantidad de gránulos, limitados por los bordes del conjunto de bordes.

El medidor de los parámetros geométricos lee sucesivamente de la RAM los parámetros de los bordes de cada uno de los gránulos, la distancia focal del objetivo, la dimensión del receptor de la imagen del censor de vídeo en metros y píxeles, calcula la dimensión geométrica de cada uno de los gránulos en metros y graba los parámetros recibidos en la memoria RAM.

El medidor de las texturas estima la densidad del gránulo, mediante la comparación de la imagen de cada uno de los gránulos con las texturas estándar (libreria), que contienen los parámetros de los gránulos de distintas densidades. Luego el medidor de texturas calcula la masa de cada uno de los gránulos multiplicando su densidad por el volumen, omitiendo la forma elipsoidal.

En la fase final del cálculo de los parámetros en el proceso de granulado, el controlador forma el histograma de la distribución de las masas, dimensiones y la cantidad de gránulos, el cual mediante el módulo de comunicación es enviado al operador, para su posterior utilización en el proceso de producción de los gránulos.

La calibración y la definición de los parámetros necesarios para el trabajo correcto del sistema de visión artificial propuesta, pueden ser realizadas de conformidad con $[7,8]$. El módulo 2 del sistema, es aconsejable realizar (a excepción de la memoria RAM y el controlador) en un circuito integral lógico programado [9].

\section{PROPUESTA EXPERIMENTAL}

Para la comprobación experimental del funcionamiento del sistema de la visión artificial propuesto, fue realizada una maqueta (fig. 2 y 3(a)), que consiste en una videocámara Logitech 9000 con un lente varifocal de $5.60 \mathrm{~mm}$, una cámara fotográfica Canon 50d con objetivo Sigma de 120-400 mm, una PC y una lámpara de luz infrarroja con una potencia de $5 \mathrm{~W}$. Para la imitación de la caída de los gránulos del tamiz y la regulación de la altura y la velocidad de su caída, es establecido a un lado y de manera rígida un plano inclinado de panel de yeso. En vez de los gránulos son usados bolitas de arcilla expandida (fig. 3(b)). Los gránulos que caen se recogen en un contenedor. La videocámara y la cámara fotográfica son ajustadas de tal manera para que la lente capture solamente la zona de caída de los gránulos a $20 \mathrm{~cm}$ de altura. 


\section{Gránulos}

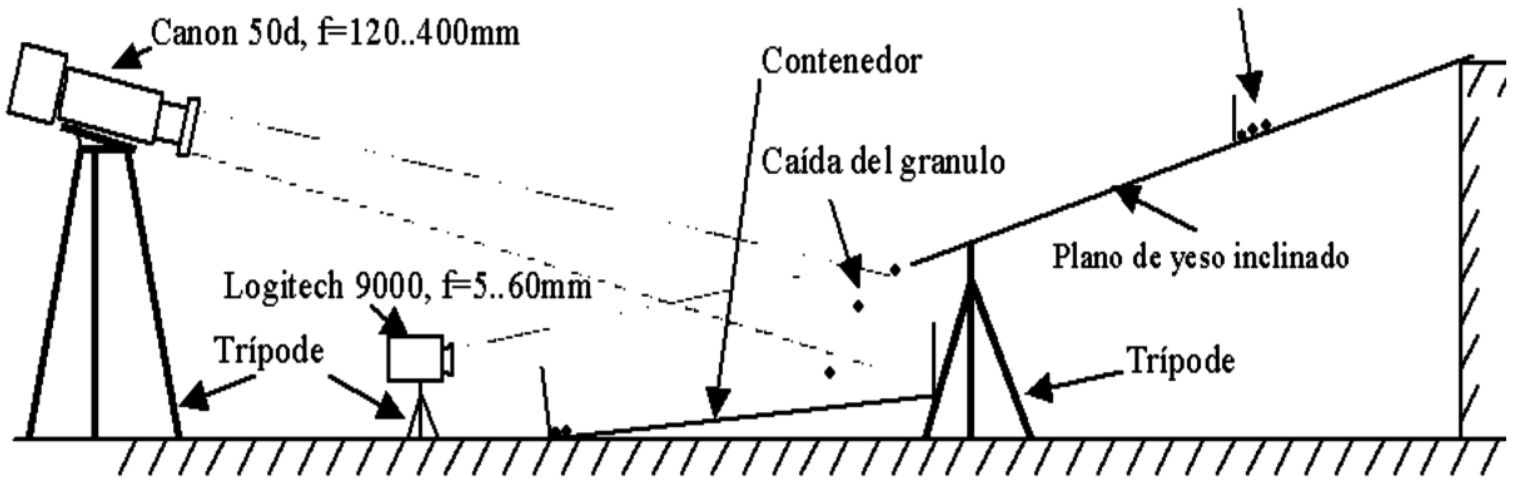

Figura 2. Maqueta del sistema de la visión artificial para el análisis de la composición granulométrica de los gránulos del mineral de hierro

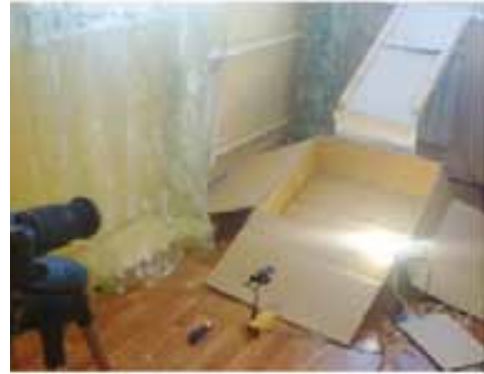

a)

Figura 3. a) Fotografías de la maqueta, b) "los gránulos" (bolitas de arcilla expandida)

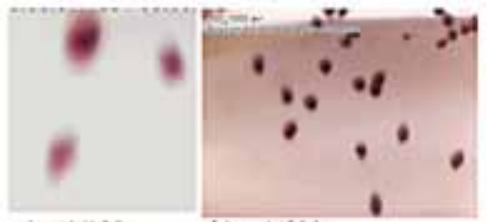

a) $\mathrm{t}=1 / 120 \mathrm{~s}$

b) $t=1 / 500 \mathrm{~s}$

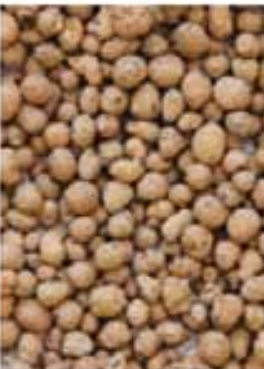

b)

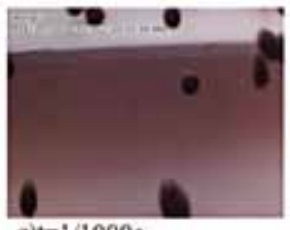

Figura 4. Imágenes de los gránulos, recibidos con la videocámara

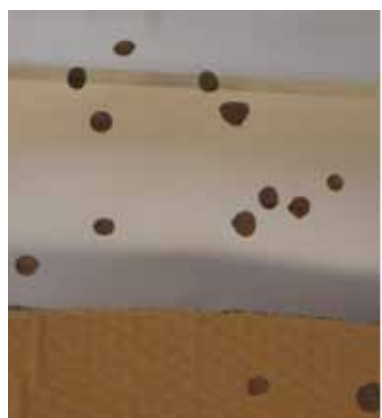

a) todo el cuadro, $t=1 / 3200 \mathrm{~s}$

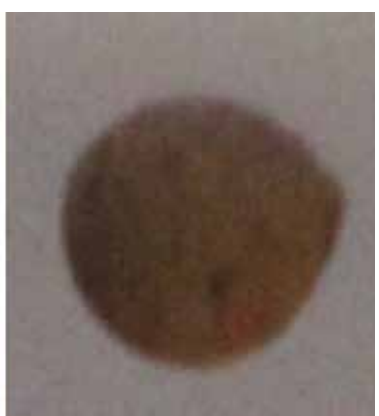

b) acercamiento de un gránulo
Figura 5. Imágenes de los gránulos, recibidas con la cámara fotográfica
El experimento consiste en lo siguiente: por medio de la videocámara Logitech 9000 con tres diferentes velocidades de obturación de 1/120s, 1/500s, 1/1000s se reciben imágenes de los gránulos. Además se estableció que las velocidades de obturación 1/120s (fig. 4a) y 1/500s (fig. 4b) no proporcionan imágenes claras debido a la gran velocidad de caída de los gránulos. La velocidad de obturación de 1/1000s (fig. 4c), se puede utilizar para medir el tamaño de los gránulos, pero no es adecuado para el análisis de su textura. Debido al hecho de que el Logitech9000 de la videocámara no permite una velocidad de obturación más rápida, fue usada la cámara fotográfica.

La obtención de las imágenes de los gránulos se realizaba con las velocidades de obturación de 1/2000s, 1/2500s, 1/3200s. Se ha comprobado que la obturación de $1 / 3200$ s es suficiente para analizar la textura de los gránulos (Fig. 5).

La estimación de error por medio de la comparación entre las dimensiones de los gránulos medidos con un compás y las imágenes recibidas ha mostrado un error promedio de 0,4mm usando la videocámara, y de 0,1 mm con el uso de la cámara fotográfica.

\section{BIBLIOGRAFÍA}

[1] Chernetskaya, I.E. Teoría del control en el proceso de granulación de materiales granulados [Texto]: monografía / E.A.Isáev, I.E.Chernetskaya, L.N.Kraht, S. S.Titov-Stariy Oskol, editorial «Tecnologías finas de alta capacidad científica», 2004. 384 pag. 
[2] Patente. 2322519 Federación Rusa, MPK C22B 1/14. El modo del control en el proceso de granulación de los materiales granulados finamente molidos [Texto] / Chernetskaya I.E., Isáev E. A - № 2006106079/02; declarado 26/02/2006; publicado en el Boletín № 11, 20/04/2008.

[3] Ершов, E.V. Sistema óptico-electrónico del control de la aglomeración de шихты [Texto] / E.V.Ershov // Censores y sistemas. - 2007, № 7. - Pag.36 - 41.

[4] E.V.Ershov, V.V. Selivanovsky etc. Control óptico-electrónico del encendido de la mezcla y la composición granulométrica del aglomerado / Monografía. - Cherepovets, El establecimiento estatal de enseñanza de la formación superior profesional de la universidad estatal de Chelyabinsk, 2007.

[5] Гридин, S. N. Sistemas de la visión artificial adoptivos / V.N.Gridin, V.S.Titov, M.I.Trufanov; Centro de las tecnologías de la información en el diseñado de la Academia de las Ciencias de Rusia. ISBN 978-5-02-025391-9. -M: Ciencia, 2009. - 441pag.

[6] Труфанов, M.I . Rasgos de los modos de calibración de los sistemas de la visión artificial [Texto] / M.I.Trufanov, T.A.Shirabakina, S.S.Tevs //Censores y sistemas. №5. 2005. - Pag.63-65.

[7] Patente. №2315965 Federación Rusa, MKI G01M11/02. Modo de la medida de los parámetros de los sistemas ópticos [Texto] / E.I.Bugaenko, el V.S.Titov, M.I.Trufanov. - №2005137291/28; es declarado 30/11/2005; publicado 27.01.08, Boletín №3.-8 pag.

[8] Титов, V.S. Los algoritmos orientados a los aparatos y los dispositivos del tratamiento de las imágenes con esquemas integrales para los sistemas de la visión artificial de captura / V.S.Titov, M.I.Trufanov//Censores y sistemas. №8. 2009. pag. $72-75$.

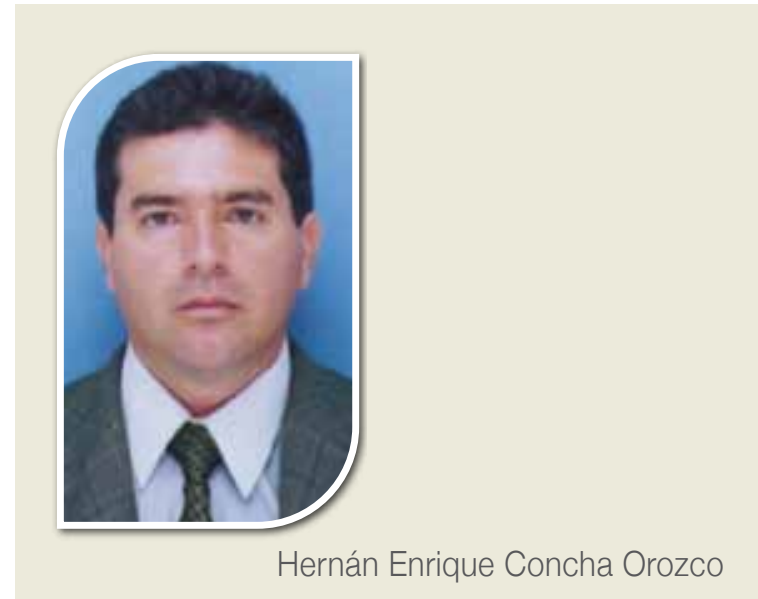

En 1995 obtiene el Título de Ingeniero Eléctrico, especialidad "Suministro de Energía Eléctrica", en la Universidad Técnica Estatal de Kursk en la Facultad de Ingeniería en Computación y Automatización.

Se ha desempeñado como ingeniero consultor y contratista en diferentes proyectos para empresas como CEDELCA S.A. E.S.P.

En la actualidad es estudiante de Doctorado de la Universidad del Sur-Oeste de Federación de Rusia 